\title{
Simulation Analysis Spray of the Butanol and Diesel Fuel Mixed with Injection Pressure and Air Flow Intensity
}

\author{
Jian $\mathrm{Wu}$ \\ College of Vehicle and Traffic Engineering \\ Henan University of Science and Technology \\ Luoyang, China \\ e-mail: wujian@haust.edu.cn
}

Weiwei Shang

College of Vehicle and Traffic Engineering Henan University of Science and Technology

Luoyang, China

e-mail: 271254456@qq.com

Yibin Liu

College of Vehicle and Traffic Engineering

Henan University of Science and Technology

Luoyang, China

e-mail: lyb900909@163.com

\author{
Yang Hua \\ College of Vehicle and Traffic Engineering \\ Henan University of Science and Technology \\ Luoyang, China \\ e-mail:1046361149@qq.com
}

\author{
$\operatorname{Bin} \mathrm{Xu}$ \\ College of Vehicle and Traffic Engineering \\ Henan University of Science and Technology \\ Luoyang, China \\ e-mail: xubin@haust.edu.cn
}

\begin{abstract}
In order to study the feasibility of the butanol as substitute fuel of diesel, the visualization experiment of spray characteristics on butanol diesel mixed fuel was carried out, using the software Fire of the company of AVL to establish a simulation model of n-butyl alcohol diesel spray and calculating the spray characteristics of $\mathrm{N} 25$ mixed fuel on the different turbulence intensity and different injection pressure, and contrast the result of experiment, and then analysis the velocity distribution and concentration distribution, spray penetration and Sauter Mean Diameter of the mixed fuel under the injection pressure of $120 \mathrm{MPa}$. The results show that the fuel spray penetration decreases continuously and Sauter Mean Diameter increase gradually with the strength of the airflow; from the velocity distribution as a result of the action of air flow the spray of mixing fuel take place of deflection, the droplets falling speed in the spray center. From the concentration distribution it can be seen that the fuel droplet concentration distribution influenced by the turbulence intensity is very important.
\end{abstract}

Keywords-Diesel; Butanol; Numerical simulation; Turbulence; Spray characteristics

\section{INTRODUCTION}

With the problem of environment increasingly serious, especially the fog weather in recent years, it has required higher demand for the emissions of diesel engine, the traditional fossil fuels cannot meet the requirements of increasingly stringent emission regulations[1-2]. Butanol as substitute fuel has many advantages, such as can very good miscibility with diesel, high calorific value, good economy, not only can satisfy the emission regulations but also ensure the performance of engine[3].Studying the butanol as substitute fuel of diesel not only reduce our dependence on fossil fuels, but also reduce pollution to the environment.

The fuel of spray and atomization quality has a greatly affect emissions on diesel engine; the combustion chamber air movement has lots of help for the formation of mixture and the quality between the air and fuel[4]. The study of butanol and diesel fuel mix mainly concentrated on the combustion and emission[5-7], the mixed fuel spray characteristics under different flow intensity of study is less. This paper based on the constant volume chamber, high-speed cameras and schlieren system as the experimental platform, setting up the spray model with Fire to simulate calculation the mixed fuel spray characteristics under different injection pressure and different airflow intensity. Then we can conclude that spray development, velocity distribution and concentration distribution, spray penetration and SMD with the different turbulence intensity and injection pressure. This can be accurate analysis and provide some reference for subsequent experiment.

\section{FUEL SPRAY TEST EQUIPMENT AND RESEARCH METHOD}

Spray visualization device schematic diagram is shown in Fig.1; there is high pressure common rail injection system, fuel injection system, measurement control system, schlieren system, high-speed camera, the 
constant volume chamber. Two types of fuel are used in the process of pure diesel (D100) and adding 10\% n-butyl alcohol by volume in the diesel made from butyl alcohol and diesel fuel mix (N10) in this test. The common rail pressure of injection is $120 \mathrm{MPa}$, and the pressure of constant volume chamber is setting in $2 \mathrm{MPa}$ by filling the nitrogen. During injection, through 10000 frames per second high-speed camera spray process, to getting the spray picture. The spray of macroscopic parameters is obtained by take photos in the process of spray; provide the basis for simulation model calibration.

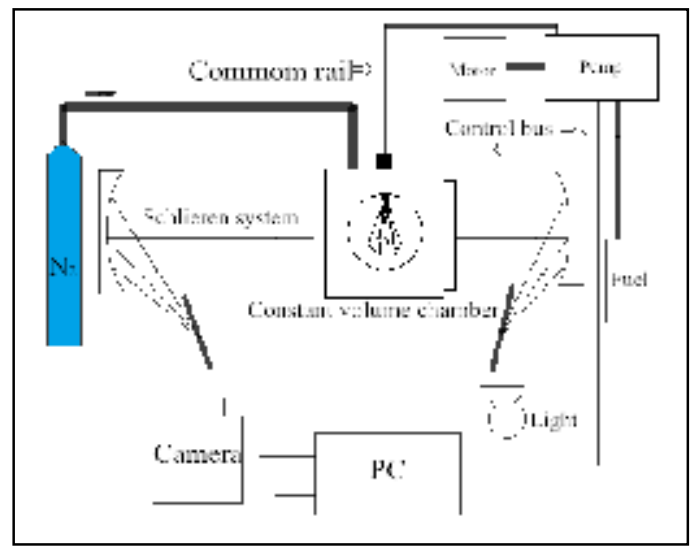

Figure 1. Diagram of the spray test

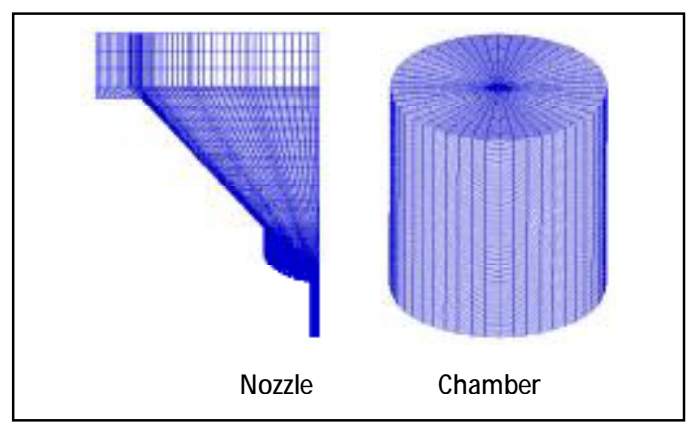

Figure 2. The grid of computational

\section{THE ESTABLISHMENT OF CALCULATION MODEL}

\section{A. Computational grid}

Using Solidworks to set up 3D geometric model on $\mathrm{BOSH}$ single hole injector before simulation calculation, the length of injector nozzle is $0.65 \mathrm{~mm}$, and the diameter $0.13 \mathrm{~mm}$. Due to the symmetry of injector nozzle, choosing a quarter as the calculating model. Simplifies the calculation of fuel spray in a cylinder of $\varnothing 80 \times 120 \mathrm{~mm}$, the position of the nozzle is in the center of the top surface of the model. Use of FAME grid generation tool to nozzle and constant volume chamber mesh as shown in Fig.2. In order to accuracy and real of the spray simulation, calculation the flow inside of the nozzles as the initial conditions and boundary conditions for different turbulence intensity and pressure of injection in the mixed fuel spray simulation calculation.

\section{B. Boundary conditions and related model}

Choosing k-epsilon as turbulence model based on the simulation of mixed fuel spray characteristics in the process of spray, and the evaporation model is Multi-component, primary crushing model is Blob
Injection, broken model is KHRT, and particle collision model is Schmidt. The initial boundary condition of spray simulation calculation in constant volume is the boundary of the internal nozzle flow calculation. The constant volume chamber pressure is $2 \mathrm{MPa}$, and temperature is $293.15 \mathrm{~K}$.

\section{Physical parameters and calculation conditions}

Fuel used in this paper physical parameters is measured as shown in TABLE I . Tests choose pure diesel and mixtures with $10 \%$ (denoted by N10) volume ratio of n-butyl alcohol. Using mixed fuel of n-butyl alcohol volume $25 \%$ with diesel fuel, for $\mathrm{N} 25$, simulation calculation different turbulence intensity and injection pressure of spray characteristics.

TABle I. Physical Paramenters Of Diesel AND Mixed

\begin{tabular}{|c|c|c|c|}
\hline Physical Features & D100 & N10 & N25 \\
\hline density $/ \times 103 \mathrm{~kg} \cdot \mathrm{m}^{-3}$ & 0.858 & 0.852 & 0.845 \\
\hline Dynamic viscosity $/ \times 10^{-3} \mathrm{~Pa} \cdot \mathrm{s}$ & 4.050 & 3.715 & 3.507 \\
\hline Surface tension $/ \mathrm{mN} \cdot \mathrm{m}^{-1}$ & 29.22 & 26.27 & 25.62 \\
\hline
\end{tabular}

The end of the turbulence intensity in the engine compression process has a significant impact to spray, but if you want to know the actual injection in cylinder air movement and strength, it has difficulty for the present conditions[8]. Based on Williams T J[9] put forward a kind of approximate calculation of half open chamber compression end airflow rate, the gas flow of method of simulation calculation to simplified as eddy motion, regardless of the extrusion flow. The simulation calculation of the flow rate is $3000 \mathrm{r} / \mathrm{min}, 4000 \mathrm{r} / \mathrm{min}$, $5000 \mathrm{r} / \mathrm{min}$ and $6000 \mathrm{r} / \mathrm{min}$. The injection pressure is $60 \mathrm{MPa}, 80 \mathrm{MPa}, 100 \mathrm{MPa}$ and $120 \mathrm{MPa}$.

\section{The results of simulate and experiment}

Fig. 3 is the contrast of experiment and simulation on D100 and N10 the spray penetration under the injection pressure $120 \mathrm{MPa}$ with the back pressure is $2 \mathrm{MPa}$. As show in Fig.3, no matter the value at any moment or the overall trend between the experiment and numerical simulation of spray penetration are all fit well, and the error is within $10 \%$. Fig.4 is the contrast of shape and spray penetration of N10 between experiment and numerical simulation, it can be seen that the results of calculation with model and test results are in good consistency. We can be thought that the calculation model is correct and reasonable, which can be used to study the mixed fuel spray.

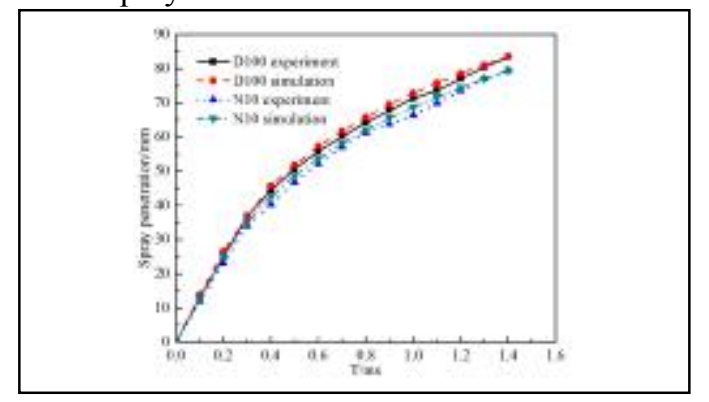

Figure 3. Spray penetration contrast 


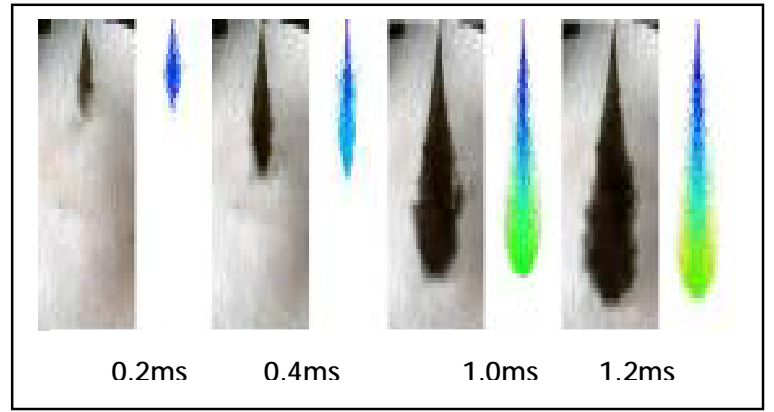

Figure 4. Spray growth process contrast

\section{RESULTS AND ANALYSIS}

Calculation the spray characteristics of mixed fuel of N25 under different flow intensity with the software of AVL Fire. Compared the spray development under fuel

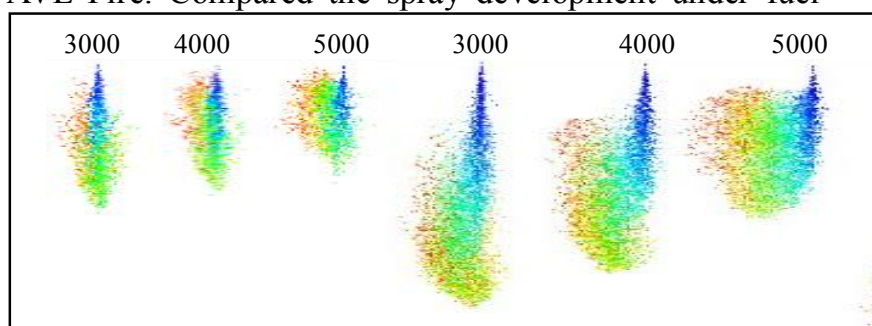

$0.3 \mathrm{~ms}$

$0.7 \mathrm{~ms}$

injection pressure is $120 \mathrm{MPa}$, and velocity distribution and concentration distribution, then comparative analysis the spray development, spray penetration and SMD under the same kind of turbulence intensity condition.

\section{A. Spray development under different turbulence intensity}

Fig. 5 is the calculation of spray development of N25 mixed fuel in the injection pressure of $120 \mathrm{MPa}$ under different turbulence intensity. The differences of shape under different turbulence intensity in the picture mainly manifested in throughout the spray penetration and the deflection effect by flow strength. With the increase of turbulence intensity, the spray penetration gradually decreases, and deflection increases, and this phenomena is evident when the turbulence intensity to $5000 \mathrm{r} / \mathrm{min}$.

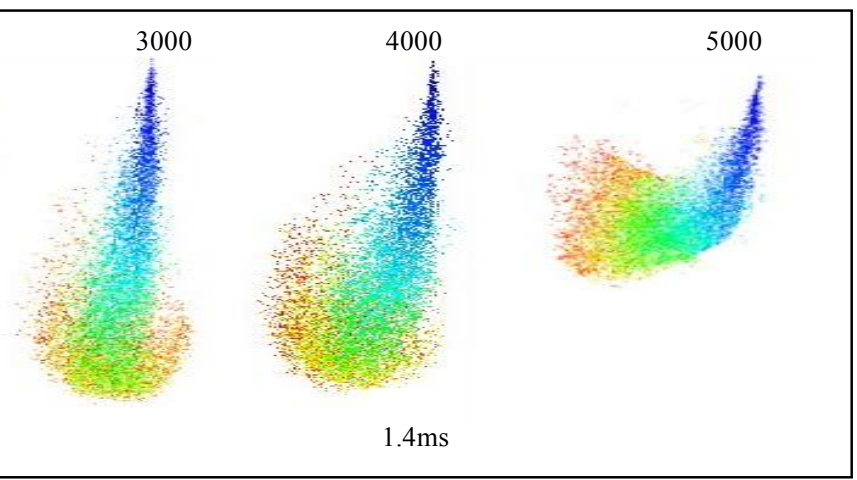

Figure 5. N25 spray growth process under different air strength

\section{B. The velocity distribution under different turbulence intensity}

Fig. 6 is the velocity distribution of mixed fuel N25 spray process with the injection pressure of $120 \mathrm{MPa}$ under different turbulence intensity. We can see that the darker area is in the center of spray, and the dark area decrease with the increase of turbulence intensity and color becomes shallow, it shows that with the increase of turbulence intensity fuel droplet decrease the speed of the spray center, with the air strength increase the area of larger value velocity of droplets in the center decreases. Because of air movement increased, enhanced energy exchange between the fuel liquid outer spray with the center of the droplet, the velocity of the droplets in the center of spray gradually reduce[10]. It can be seen that the velocity of spray in the center is largest in any turbulence intensity, and gradually reduce from center to outward. This is because the outside of the spray continuously carrying on the entrainment interactions with the air, the fuel droplets in the center squeeze air to outward continuously, energy exchange fast and energy loss larger, compared to the center of fuel droplets does not directly contact with air, the velocity decreases gradually from center to outward[10]. In addition, with the increase of turbulence intensity, the degree of deflection of spray gradually increases.

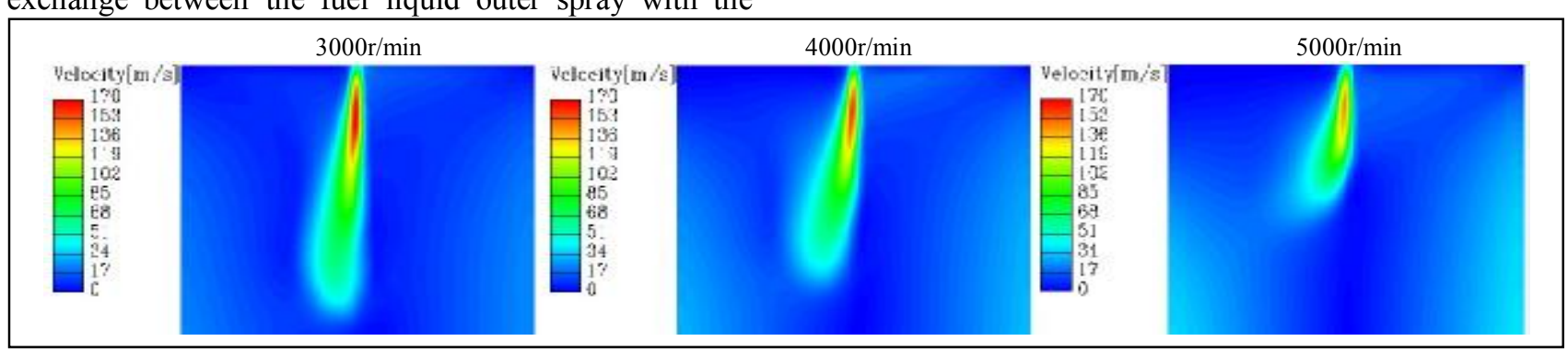

Figure 6. $1.4 \mathrm{~ms}$ velocity distribution of N25 under different flow intensity

\section{Concentration distribution under different turbulence intensity}

Fig.7 is the simulation of mixed fuel N25 droplet concentration distribution with the injection pressure of $120 \mathrm{MPa}$ under different turbulence intensity. At the same moment the large concentration of injection fuel droplet is in the center of spray under different turbulence intensity distribution. We can see that the smaller of the droplet concentration is in the outward of the spray, and with the increase of turbulence intensity the center of spray fuel droplet distribution gradually concentrated, especially under the bigger air flow intensity. We can also 
see that the spray deflection intensified due to the air flow, makes the distribution of fuel droplet concentration appears asymmetric, especially under the strength turbulence intensity. This is because airflow movement help heat exchange between fuel and air decreases the time of fuel droplet evaporation, and air entrainment effect enhanced fuel droplet breakage more rapidly[11].
But when the turbulence intensity increases to $5000 \mathrm{r} / \mathrm{min}$, the airflow movement too strong lead to spray deflection increases, spray penetration decreases, and collision between axial droplet spray and the rate of polymerization increases, cause a large concentration of fuel droplet distribution area larger[12].

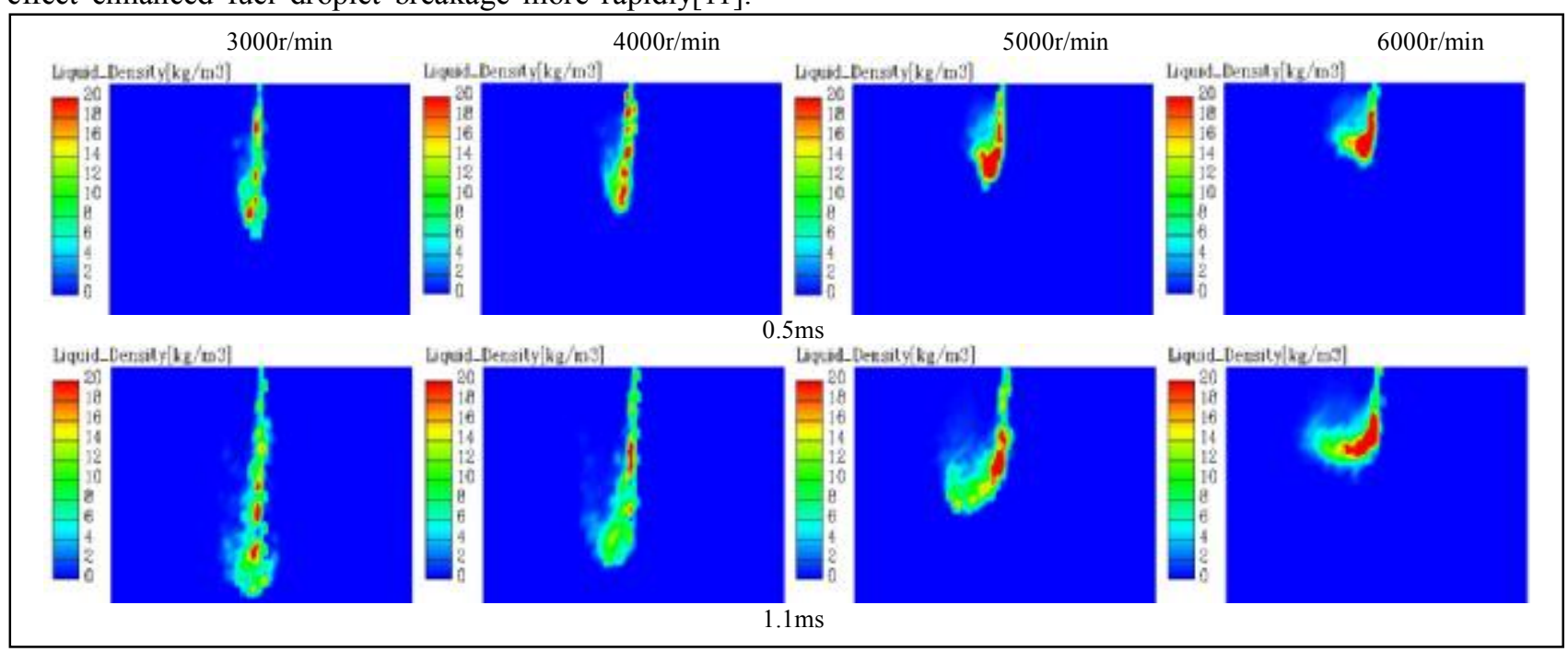

Figure 7. Different time droplet concentration under different turbulence intensity

\section{The spray penetration and SMD under different turbulence intensity}

Fig.8 is the simulation calculated of the spray penetration with the N25 injection pressure of $120 \mathrm{MPa}$ under different turbulence intensity. The mixed fuel spray penetration gradually reduce as turbulence intensity increasing; after $0.2 \mathrm{~ms}$ the gap distance of spray penetration gradually increases under different turbulence intensity. This is due to the air flow movement increase, on the one hand lead to fuel liquid and air entrainment, on the other hand the front of spray and droplets collision energy loss is fast, droplet axial velocities decreases, and spray penetration decrease with the turbulence intensity increase[13].

Fig.9 is the simulated calculated SMD with N25 injection pressure of $120 \mathrm{MPa}$ under different turbulence intensity. We can see that the SMD of mixed fuel reduced fast under different turbulence intensity at the beginning of injection, the rate of constantly decreases with the jet continue, and the curves in flat in the later stages of the simulation. It also can be seen in the diagram that the SMD of $3000 \mathrm{r} / \mathrm{min}$ and $4000 \mathrm{r} / \mathrm{min}$ is smaller than $5000 \mathrm{r} / \mathrm{min}$ and $6000 \mathrm{r} / \mathrm{min}$ after $0.5 \mathrm{~ms}$ airflow intensity; the change trend of droplet SMD is small and smaller difference with the change of time under turbulence intensity of $3000 \mathrm{r} / \mathrm{min}$ and $4000 \mathrm{r} / \mathrm{min}$, and the $5000 \mathrm{r} / \mathrm{min}$ and $6000 \mathrm{r} / \mathrm{min}$ is similar. This is mainly because the fuel and air entrainment effect strengthen under the weak turbulence intensity, the liquid more easily broken, the SMD reduced. When the turbulence intensity continues to increase, increases the probability of collision between droplets and rejoin, fuel SMD larger.

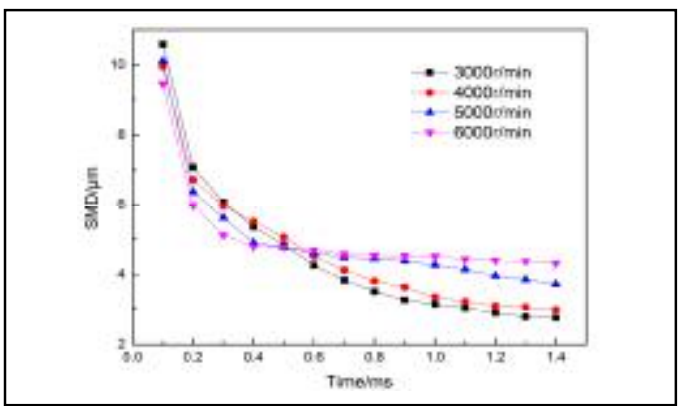

Figure 8. Spray penetration contrast

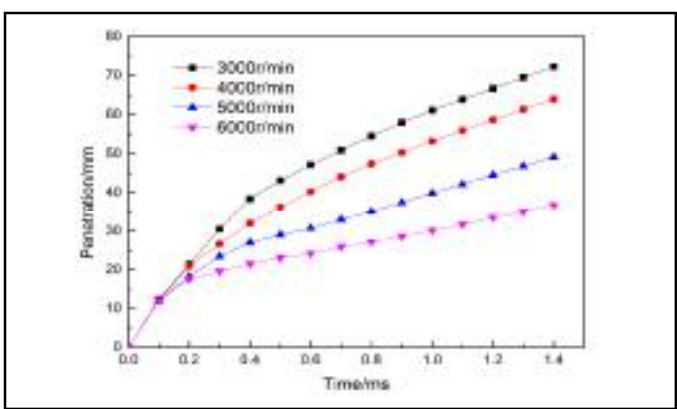

Figure 9. SMD contrast

\section{E. Spray development under the same flow intensity of} different injection pressure

Fig.10 and Fig.11 are the fuel beam growth process with N25 mixed fuel under different injection pressure with the flow intensity of $3000 \mathrm{r} / \mathrm{min}$ and $4000 \mathrm{r} / \mathrm{min}$. We can see that there is the same trend on the shape of spray under different turbulence intensity, spray deflection gradually increased with turbulence intensity increase, and spray penetration gradually decrease, and the front of spray area gradually increase, the spray cone angle 
increase, the front of spray form full, particularly evident when turbulence intensity strength. It shows difference is caused by the fuel droplets collision with air range become shorter, in addition, due to the increase of the airflow, enhanced spray lateral diffusion. Also can be seen that spray deflection is the air flow, fuel injection pressure has certain influence to the spray deflection, the greater the fuel injection pressure, the smaller spray deflection under the same flow intensity. But it is obviously effect on the injection pressure for the spray penetration under the same flow intensity injection pressure. Because the injection pressure increase, the momentum of droplet increases, and the effect of horizontal airflow is abate.

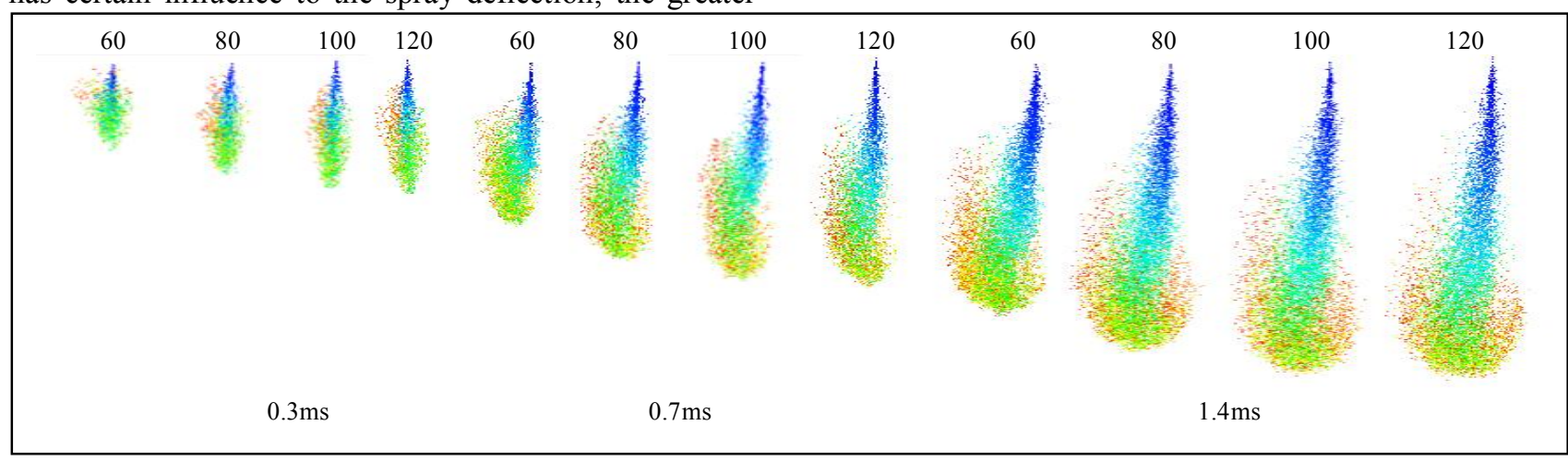

Figure 10. Spray development under different injection pressure with $3000 \mathrm{r} / \mathrm{min}$

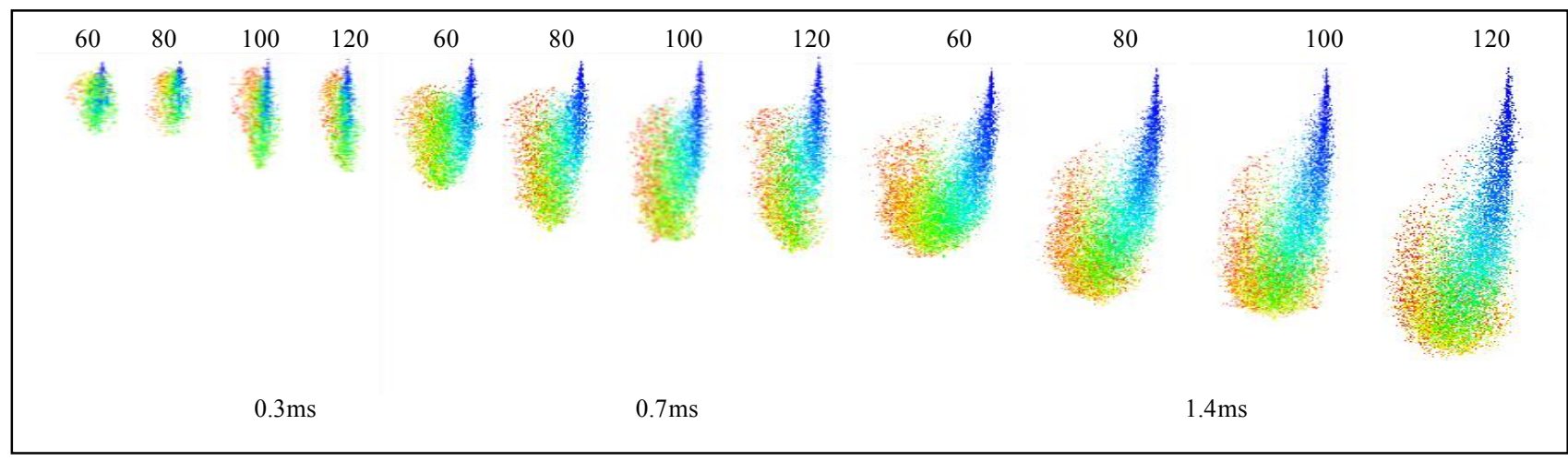

Figure 11. Spray development under different injection pressure with $4000 \mathrm{r} / \mathrm{min}$

\section{F. Spray penetration and SMD under the same airflow intensity with different injection pressure}

Fig. 12 and Fig. 13 are the contrast of spray penetration and SMD under different injection pressure with the turbulence intensity $4000 \mathrm{r} / \mathrm{min}$. It can be seen that the SMD decrease and the spray penetration increase with the increase of injection pressure in the same kind of turbulence intensity. Fuel droplet initial momentum increase with the increase of injection pressure, spray penetration increases, the relative velocity increases between the droplet and gas, the droplet surface temperature accelerated evaporation, and SMD decreased.

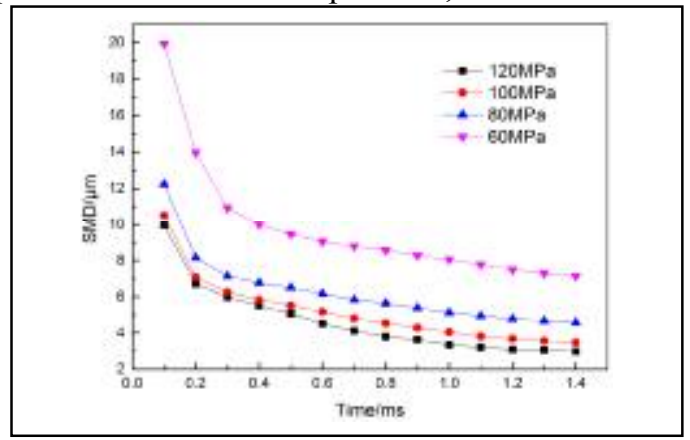

Figure 12. Spray penetration contrast

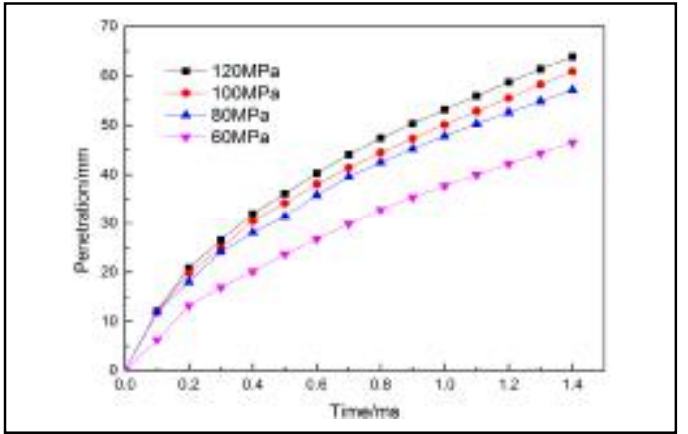

Figure 13. SMD contrast

\section{CONCLUSIONS}

There is good result of calculation and model established by 3D software FIRE of AVL. With the increase of turbulence intensity spray shape differences on the macroscopic characteristics of spray within a certain range, when the flow reaches a certain value the fuel spray penetration decrease, spray deflection increasing. From the velocity distribution of fuel spray can be seen that with the increase of turbulence intensity the air entrainment is strength, and high velocity distribution appear in the center of spray under each flow; from the concentration distribution can be seen that the area of fuel droplet become concentration with the 
increase of turbulence intensity, the outward droplet concentration of spray decreases, indicating that airflow helps to improve the fuel atomization. There is less effect to the SMD with the turbulence intensity, but it is obvious for the spray penetration. When air flow increased to a certain value the spray penetration will be significantly shorter, and SMD increases.

\section{REFERENCES}

[1] Jiang D.M. \& Huang, Z.H., Internal combustion engine alternative fuel combustion, Xi'an: Xi'an Jiaotong University Press,2007.

[2] Reitz R.D., Directions in internal combustion engine research. Combustion and Flame, 160(1),pp.1-8, 2013.

[3] Liu Y. \& Liu H.J., The research progress of new biofuel butanol, The modern chemical industry, 28(6),pp. 2-3,2008.

[4] Zhou L.B., The theory of internal combustion engine, Beijing: Mechanical Industry Press, 2010.

[5] Hang W., Diesel butanol mixed fuel on diesel engine working process and the impact of emissions, Hefei University of Technology, 2013.
[6] Zhang Q.C., Yao M.F., Experimental study of n-butanol addition on performance and emissions with diesel low temperature combustion. Energy,47,pp.515-521,2012.

[7] Rakopoulos D.C. \& Hountalas D.T. Investigation of the performance and emissions of bus engine operating on Butanol/Diesel fuel blends. Fuel,89(10),pp.2781-2790,2010.

[8] Liang L., Strength of eddy current effect on spray the numerical simulation, Chongqing: Chongqing Jiaotong University, 2008.

[9] Williams T. J. \& Tindal M. J., The Predication and measurement of Gas Flow in the combustion Chamber of D.I.Diesel Engines. CIMAC,13,D24, 1979

[10] Hu Y., Ethanol spray characteristics of numerical simulation in cylinder, Wuhan University of Technology, 2011.

[11] Xu F., The principle of internal combustion engine, Dalian: Dalian University of Technology Press,2011.

[12] Du H.Y. \& Zhang Q.F., Airflow disturbances affect oxygen fuel, The internal combustion engine, 1,pp.21-24,2014.

[13] Jiang L. \& Ge Y.S., The numerical simulation of biodiesel fuel spray characteristics. The internal combustion engine engineering, 30(5),pp.17-21,2009 